\title{
INFLUENCE OF LIGHT ABSORPTION PROFILE ON THE PERFORMANCE OF ORGANIC PHOTOVOLTAICS
}

\author{
ABdul HALIM IKRAM MOHAMED ${ }^{1}$ AND MOHD LUKMAN INCHE IbRAHIM ${ }^{2}$ * \\ ${ }^{I}$ Department of Electrical and Computer Engineering, \\ ${ }^{2}$ Department of Science in Engineering, \\ Kulliyyah of Engineering, International Islamic University Malaysia, \\ Jalan Gombak, 53100 Kuala Lumpur, Malaysia. \\ *Corresponding author: lukmanibrahim@iium.edu.my
}

(Received:23 $3^{\text {rd }}$ June 2020; Accepted: $16^{\text {th }}$ January 2021; Published on-line: $4^{\text {th }}$ July 2021)

\begin{abstract}
We investigate how an enhanced light absorption at a specific position inside the active layer affects the performance of organic photovoltaic cells (OPVs), namely the short-circuit current density $\left(J_{s c}\right)$, the open-circuit voltage $\left(V_{o c}\right)$, the fill factor $(\mathrm{FF})$, and the power conversion efficiency (PCE). The performance is calculated using an updated version of a previously published analytical current-voltage model for OPVs, where the updated model allows the light absorption profile to be described by any functions provided that analytical solutions can be produced. We find that the light absorption profile affects the performance through the drift current. When the mobility imbalance is not very high (when the ratio of the mobility of the faster carrier type to the mobility of the slower carrier type is less than about $10^{3}$ ), the PCE is maximized when the light absorption is concentrated at the center of the active layer. When the mobility imbalance is very high (when the ratio of the mobility of the faster carrier type to the mobility of the slower carrier type is more than approximately $10^{4}$ ), the PCE is maximized when the light absorption is concentrated near the electrode collecting the slower carrier type. Therefore, it is important to ensure that the light absorption profile is properly tuned so that the performance of OPVs is maximized. Moreover, any efforts that we make to improve the performance should not lead to a light absorption profile that would actually impair the overall performance.
\end{abstract}

ABSTRAK: Kajian ini menilai bagaimana penyerapan cahaya yang tinggi pada bahagian tertentu lapisan aktif mempengaruhi prestasi sel fotovoltaik organik (OPV), iaitu ketumpatan arus litar pintas (Jsc), voltan litar terbuka (Voc), faktor pengisian (FF), dan kecekapan penukaran kuasa (PCE). Prestasi dikira mengguna pakai model terkini yang diperbaharui dari model asal analitikal OPV voltan-arus, di mana model ini membenarkan mana-mana profil penyerapan cahaya digunakan asalkan penyelesaian analitikal terhasil. Dapatan kajian mendapati profil penyerapan cahaya mempengaruhi prestasi berdasarkan arus hanyut. Apabila ketidakseimbangan pergerakan caj tidak begitu tinggi (di mana nisbah pergerakan pembawa caj laju kepada perlahan adalah kurang daripada $10^{3}$ ), PCE menjadi maksimum jika penyerapan cahaya bertumpu pada tengah lapisan aktif. Apabila ketidakseimbangan pergerakan caj sangat tinggi (di mana nisbah pergerakan pembawa caj laju kepada perlahan adalah lebih daripada $10^{4}$ ), PCE menjadi maksimum jika penyerapan cahaya bertumpu pada elektrod yang mengutip pembawa caj perlahan. Oleh itu, kedudukan talaan profil penyerapan cahaya yang tepat adalah sangat penting bagi menentukan prestasi OPV dimaksimumkan. Tambahan, apa sahaja usaha penambahbaikan prestasi seharusnya tidak menyebabkan pengurangan keseluruhan prestasi profil penyerapan cahaya. 
KEYWORDS: carrier mobility; fill factor; open-circuit voltage; power conversion efficiency; short-circuit current

\section{INTRODUCTION}

Organic photovoltaic cells (OPVs) have several unique advantages such as lightweight, high mechanical flexibility, good transparency, and low fabrication cost [1]. Hence, OPVs are viewed as a promising alternative to conventional photovoltaic technologies. For example, OPVs have a great potential to be used for powering various devices such as wearable devices [1], next generation self-driven biomedical devices [2], and off-grid devices for the Internet of Things [3]. The recorded power conversion efficiency (PCE) of OPVs has been improving steadily from 11\% [4] several years ago to $17.3 \%$ currently [5]. However, the PCE of OPVs is still quite low compared with traditional photovoltaics, and even when compared with another emerging photovoltaic technology, namely perovskite solar cells [4]. Therefore, improving the performance has been a focus of OPV research.

There are many factors that influence the performance of OPVs such as the carrier mobility [6,7], the work function of the electrodes [8,9], the permittivity of the active layer $[7,10]$ and the thickness of the active layer [11-13]. The light absorption profile inside the active layer has been reported to be another factor that influences the performance [14-16]. The light absorption profile is determined by several factors such as the optical properties of the OPV components and the thickness of the active layer [13].

An improvement in the PCE by optimizing the light absorption profile can be achieved in practice since the absorption profile can be controlled to a certain extent. For example, optical spacers can be used to alter the absorption profile $[14,15]$. Another method that could be used to control the absorption profile is by employing plasmonic nanoparticles, which can be located outside or embedded inside the active layer [17]. Light intensity increases near the plasmonic nanoparticles [17], and hence, the light absorption should be higher near the nanoparticles. Therefore, one could control the absorption profile to a certain extent by choosing the embedment positions of the nanoparticles.

Although understanding the effect of the light absorption profile is clearly important, there is still a gap concerning our understanding on this matter. It has been shown that a high light absorption at a specific position inside the active layer improves the performance [14-16]. In more detail, Mescher et al. [14] and Islam et al. [16] concluded that a higher light absorption at the center of the active layer gives a better performance but did not conclude on the possible effect of carrier mobility imbalance. On the other hand, Tress et al. [15] concluded that the fill factor (FF) improves if more light is absorbed near the contact that collects the slower carrier type even when the mobility imbalance is quite low. Hence, there are still uncertainties regarding this matter. For example, from previous studies, we still have no clue on how the optimum light absorption profile evolves as the carrier mobilities evolve from balanced to highly imbalanced. Furthermore, there is a disagreement between the results of previous studies. When the mobility imbalance is quite low (when the ratio of the mobility of the faster carrier type to the mobility of the slower carrier type is of one order of magnitude), Islam et al. [16] found that the best performance is produced when the light absorption is concentrated at the center of the active layer whereas Tress et al. [15] found that the best performance is produced when the light absorption is concentrated near the electrode collecting the slower carrier type. 
In this paper, we will investigate the effect of the light absorption profile on the performance of OPVs with the aim of providing insights on how an enhanced light absorption at a specific position inside the active layer affects the OPV performance at different levels of mobility imbalance, and enlightening the disagreement between the results of previous studies.

\section{METHODOLOGY}

\subsection{Analytical Model}

The current-voltage model for OPVs presented in this section is employed for all calculations in this article. The model is essentially the same as a previously published model [18]. Therefore, finer details of the model presented here can be obtained in the published work [18]. The only difference between the model presented here and the previous model is that the charge-transfer (CT) state generation profile here is open to any functions provided that the continuity equations can be solved analytically whereas the CT state generation profile in the previous model has an exponential function. The device structure of the model is illustrated in Fig. 1.

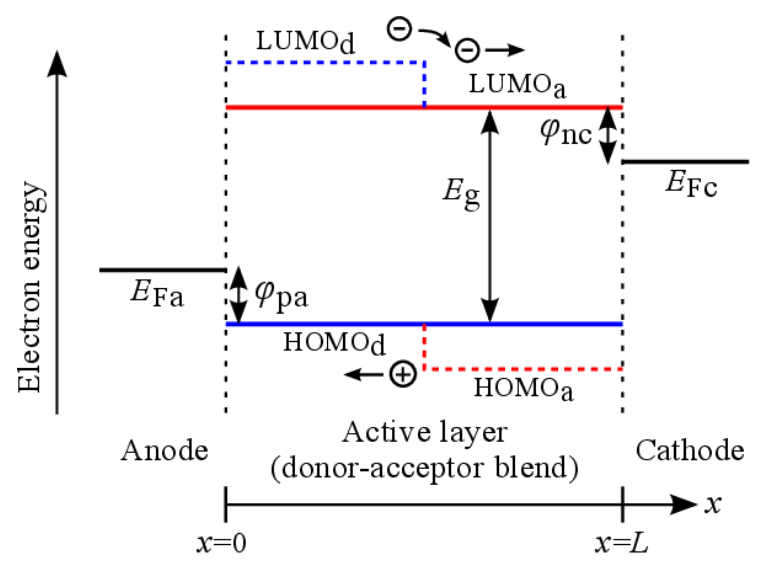

Fig. 1: A schematic showing the energy levels and the device structure. LUMOd and HOMOd denote the lowest unoccupied molecular orbital (LUMO) and the highest occupied molecular orbital (HOMO) of the donor, respectively. LUMOa and HOMOa denote the LUMO and the HOMO of the acceptor, respectively. $\mathrm{E}_{\mathrm{g}}$ denotes the effective band gap. $\mathrm{E}_{\mathrm{Fa}}$ and $\mathrm{E}_{\mathrm{Fc}}$ denote the Fermi levels of the anode and the cathode, respectively. $L$ is the thickness of the active layer. $\varphi_{\mathrm{pa}}$ and $\varphi_{\mathrm{nc}}$ denote the

hole injection barrier at anode and the electron injection barrier at cathode, respectively. In the operation of OPVs, anode is the electrode that collects free holes and cathode is the electrode that collects free electrons.

Light absorption by the active layer generates excitons. When the excitons reach the donor-acceptor interface, CT states may be produced. Free charge carriers are generated from the dissociation of the CT states. When free electrons and free holes recombine bimolecularly, CT states are produced back. Therefore, CT states can be generated due to exciton relaxations at the donor-acceptor interface (through photon absorption) and due to bimolecular recombination. Since bulk heterojunction design is used to construct the active layer, the photogenerated CT states are produced at approximately the same location where the excitons are photogenerated (or where the photons are absorbed). Therefore, the profile of the light absorption can be assumed to have the same equivalent shape as the profile of the CT state photogeneration rate. 
According to the previous model, when the non-geminate recombination is not considered in the electron (hole) continuity equation, the resulting electron (hole) density that arises from the solution of the equation is called the maximum electron (hole) density $n_{\max }\left(p_{\max }\right)$ [18]. The electron and the hole continuity equations at steady state without the non-geminate recombination are given by

$$
\begin{aligned}
& D_{n} \frac{\partial^{2} n_{\max }}{\partial x^{2}}+\mu_{n} F \frac{\partial n_{\max }}{\partial x}+P_{d} G_{C T}=0 \\
& D_{p} \frac{\partial^{2} p_{\max }}{\partial x^{2}}-\mu_{p} F \frac{\partial p_{\max }}{\partial x}+P_{d} G_{C T}=0
\end{aligned}
$$

where $D_{n}\left(D_{p}\right)$ is the electron (hole) diffusion coefficient, $\mu_{n}\left(\mu_{p}\right)$ is the electron (hole) mobility, $F$ is the electric field, $P_{d}$ is the dissociation probability of CT states, and $G_{C T}$ is the CT state photogeneration rate per unit volume. The CT state dissociation probability is defined as

$$
P_{d}=\frac{k_{d}}{k_{d}+k_{f}}
$$

where $k_{d}$ is the CT state dissociation rate coefficient, and $k_{f}$ is the CT state decay rate coefficient. As in the previous model [18], $k_{d}$ given by the work of Inche Ibrahim [19] is used in this article, which is an improvement to the Onsager-Braun model [20].

Solving Eq. (1) and Eq. (2) are the same as solving non-homogenous second-order linear ordinary differential equations with constant coefficients where $D_{n}, D_{p}, \mu_{n}, \mu_{p}, F$, and $P_{d}$ are independent of $x$ [18] with $P_{d} G_{C T}$ being the non-homogenous term. Any functions can be assigned to the non-homogenous term (i.e. to $G_{C T}$ since $P_{d}$ is a constant) provided that Eq. (1) and Eq. (2) can be solved analytically. The boundary conditions as given in the previous model [18] are used and MATLAB is employed to analytically solve Eq. (1) and Eq. (2) to obtain $n_{\max }$ and $p_{\max }$.

Furthermore, according to the previous model [18], when the non-geminate recombination is considered in the electron (hole) continuity equation, the resulting electron (hole) density that arises from the solution of the equation is called the net electron (hole) density $n_{\text {net }}\left(p_{\text {net }}\right)$. The electron and the hole continuity equations at steady state with the non-geminate recombination considered are therefore given by

$$
\begin{aligned}
& D_{n} \frac{\partial^{2} n_{n e t}}{\partial x^{2}}+\mu_{n} F \frac{\partial n_{n e t}}{\partial x}+P_{d} G_{C T}-\left(1-P_{d}\right) R_{b}-R_{m n}=0 \\
& D_{p} \frac{\partial^{2} p_{n e t}}{\partial x^{2}}-\mu_{p} F \frac{\partial p_{n e t}}{\partial x}+P_{d} G_{C T}-\left(1-P_{d}\right) R_{b}-R_{m p}=0
\end{aligned}
$$

where $R_{b}$ is the non-geminate bimolecular recombination rate per unit volume, and $R_{m n}$ $\left(R_{m p}\right)$ is the non-geminate monomolecular recombination rate per unit volume for electrons (holes). $R_{b}$ is given by

$$
R_{b}=\gamma k_{L} n_{\max } p_{\max }
$$

where $\gamma$ is the bimolecular recombination reduction coefficient, and $k_{L}$ is the Langevin recombination coefficient [18]. $R_{m n}$ and $R_{m p}$ are given by

$$
\begin{aligned}
& R_{m n}=k_{\text {mn }} n_{\text {max }} \\
& R_{m p}=k_{\text {mp }} p_{\text {max }}
\end{aligned}
$$

where $k_{m n}\left(k_{m p}\right)$ is the monomolecular recombination coefficient for electrons (holes). It is important to note that $R_{m n}=R_{m p}$ as explained in the previous model [18]. Solving Eq. 
(4) and Eq. (5) are also the same as solving second-order linear ordinary differential equations with constant coefficients. Again, the boundary conditions as given in the previous model [18] are used and MATLAB is employed to analytically solve Eq. (4) and Eq. (5) to obtain $n_{\text {net }}$ and $p_{\text {net }}$.

The electron current density $J_{n}$ and the hole current density $J_{p}$ are given by

$$
\begin{aligned}
& J_{n}=q \mu_{n} F n_{n e t}+q D_{n} \frac{\partial n_{n e t}}{\partial x} \\
& J_{p}=q \mu_{p} F p_{n e t}-q D_{p} \frac{\partial p_{n e t}}{\partial x}
\end{aligned}
$$

The total current density $J$ is the sum of $J_{n}$ and $J_{p}$. The first terms on the right sides of Eq. (9) and Eq. (10) are the electron drift current density $J_{n, d r}$ and the hole drift current density $J_{p, d r}$, respectively, whereas the second terms on the right sides of Eq. (9) and Eq. (10) are the electron diffusion current density $J_{n \text {,diff }}$ and the hole diffusion current density $J_{p, \text { diff }}$, respectively.

\subsection{Light Absorption Profiles and Parameter Values}

To achieve the objective of this paper, we need to use the light absorption profile (and hence, the $G_{C T}$ profile) that has an enhanced absorption (and hence, an enhanced CT state photogeneration rate) at a specific position inside the active layer. To produce such a profile, we use $G_{C T}$ given by

$$
G_{C T}=G_{0}+G_{1}(x-C)^{2}
$$

where $G_{0}$ and $G_{1}$ are the CT state photogeneration rate parameters, and $C$ is the location of the peak CT state photogeneration rate (or the location of the peak light absorption). The CT state photogeneration rate per unit area of the active layer is $G_{C T, \text { area }}=\int_{0}^{L} G_{C T} d x$. Hence,

$$
G_{C T, \text { area }}=G_{0} L+\frac{1}{3} G_{1}\left[(L-C)^{3}+C^{3}\right]
$$

To ensure a fair comparison, each of the studied $G_{C T}$ profile must have the same the value of $G_{C T \text {, area }}$. When $C \leq L / 2$, we impose the condition $G_{C T}(x=L)=0$. Therefore, when $C \leq L / 2$, we have

$$
\begin{aligned}
G_{1} & =\frac{3 G_{C T, \text { area }}}{C^{3}+(L-C)^{3}-3 L(L-C)^{2}} \\
G_{0} & =-G_{1}(L-C)^{2}
\end{aligned}
$$

When $C>L / 2$, we impose the condition $G_{C T}(x=0)=0$. Therefore, when $C>$ $L / 2$, we have

$$
\begin{aligned}
G_{1} & =\frac{3 G_{C T, \text { area }}}{C^{3}+(L-C)^{3}-3 L C^{2}} \\
G_{0} & =-G_{1} C^{2}
\end{aligned}
$$

In this paper, four different values of $\mu_{n} / \mu_{p}$ (ratio of the electron mobility to the hole mobility) are considered. Table 1 shows the values of $\mu_{n} / \mu_{p}$ together with the corresponding values of $\mu_{n}$ and $\mu_{p}$ used in this study. The values of the other parameters are shown in Table 2. The parameter values in Table 2 are typical for OPVs $[11,18]$, particularly OPVs based on P3HT:PCBM blend [21]. Figure 2 illustrates several $G_{C T}$ profiles used in this study. 
Table 1: Values of the electron mobility $\mu_{n}$ and the hole mobility $\mu_{p}$, and the resulting $\mu_{n} / \mu_{p}$ used in the calculations

\begin{tabular}{ccc}
\hline $\boldsymbol{\mu}_{\boldsymbol{n}}\left(\mathbf{m}^{2} \mathbf{V}^{-1} \mathbf{s}^{-1}\right)$ & $\boldsymbol{\mu}_{\boldsymbol{p}}\left(\mathbf{m}^{2} \mathbf{V}^{-1} \mathbf{s}^{-1}\right)$ & $\boldsymbol{\mu}_{\boldsymbol{n}} / \boldsymbol{\mu}_{\boldsymbol{p}}$ \\
\hline $1 \times 10^{-7}$ & $1 \times 10^{-7}$ & 1 \\
$9 \times 10^{-7}$ & $9 \times 10^{-9}$ & $10^{2}$ \\
$9 \times 10^{-6}$ & $9 \times 10^{-10}$ & $10^{4}$ \\
$3 \times 10^{-5}$ & $3 \times 10^{-10}$ & $10^{5}$ \\
\hline
\end{tabular}

Table 2: Parameter values used in the calculations unless otherwise specified. The symbols in this table are the same as in the previous works $[11,18]$

\begin{tabular}{cll}
\hline Symbols & Parameter Description & Value \\
\hline $\boldsymbol{E}_{\boldsymbol{g}}$ & Effective band gap & $1.1 \mathrm{eV}$ \\
$\boldsymbol{N}_{\boldsymbol{c}}, \boldsymbol{N}_{\boldsymbol{v}}$ & Density of states & $2 \times 10^{26} \mathrm{~m}^{-3}$ \\
$\boldsymbol{\mu}_{\boldsymbol{n} \boldsymbol{a}}$ & Actual electron mobility & $200 \boldsymbol{\mu}_{\boldsymbol{n}}$ \\
$\boldsymbol{\mu}_{\boldsymbol{p} \boldsymbol{a}}$ & Actual hole mobility & $200 \boldsymbol{\mu}_{\boldsymbol{p}}$ \\
$\boldsymbol{\varepsilon}$ & Effective permittivity of the active layer & $3 \times 10^{-11} \mathrm{~F} \cdot \mathrm{m}^{-1}$ \\
$\boldsymbol{\varphi}_{\boldsymbol{n} \boldsymbol{a}}, \boldsymbol{\varphi}_{\boldsymbol{n} \boldsymbol{c}}$ & Injection barriers & $0.05 \mathrm{eV}$ \\
$\boldsymbol{k}_{\boldsymbol{f}}$ & CT state decay rate coefficient & $1 \times 10^{8} \mathrm{~s}^{-1}$ \\
$\boldsymbol{a}$ & Electron-hole separation of the CT state & $1.8 \times 10^{-9} \mathrm{~m}$ \\
$\boldsymbol{T}$ & Temperature & $300 \mathrm{~K}$ \\
$\boldsymbol{\lambda}$ & Donor-acceptor morphology parameter & 0.15 \\
$\boldsymbol{L}$ & Active layer thickness & $100 \mathrm{~nm}$ \\
$\boldsymbol{G}_{\boldsymbol{C T}, \boldsymbol{a r} \boldsymbol{a} \boldsymbol{a}}$ & CT state photogeneration rate per unit area & $1 \times 10^{21} \mathrm{~m}^{-2} \mathrm{~s}^{-1}$ \\
$\boldsymbol{\gamma}$ & Bimolecular recombination reduction coefficient & 0.002 \\
$\boldsymbol{k}_{\boldsymbol{m} \boldsymbol{n}}$ & Monomolecular recombination coefficient for electrons & $200 \mathrm{~s}^{-1}$ \\
\hline
\end{tabular}

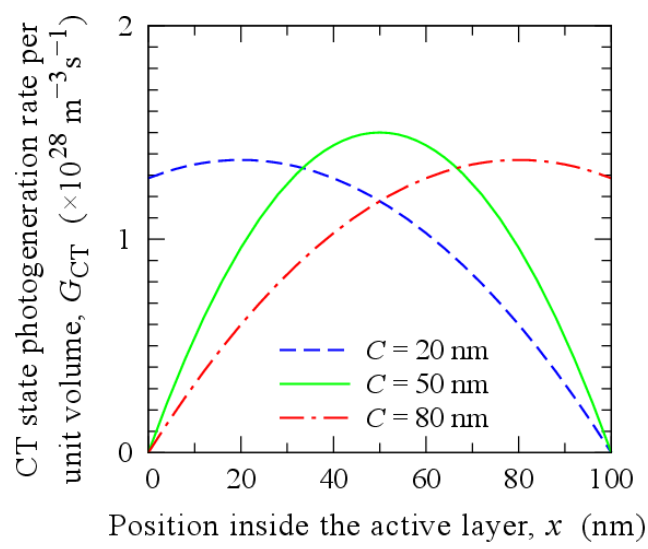

Fig. 2: Several profiles of the CT state photogeneration rate per unit volume $G_{C T}$ that are used in this study. The expression for $G_{C T}$ is given by Eq. (11). $G_{C T}$ profile with light absorption peaks $C$ at $0 \mathrm{~nm}, 40 \mathrm{~nm}, 60 \mathrm{~nm}$ and $100 \mathrm{~nm}$ are also used but are not shown in the figure.

\section{RESULTS AND DISCUSSION}

In this section, we present and discuss the results of our calculations. Different values of the carrier mobilities affect the OPV performance as shown by previous studies $[6,7,18]$. Therefore, it is imperative that we do not compare between performances of an OPV with a given $\mu_{n} / \mu_{p}$ and an OPV with a different $\mu_{n} / \mu_{p}$. What we should analyze 
here is how OPVs with different values of $\mu_{n} / \mu_{p}$ respond to different $G_{C T}$ profiles. Furthermore, for clarity and brevity of this study, we only confine our analysis from the theoretical perspective. We cannot fully control all device parameters when conducting experiments. For example, every time we use a different active layer material in order to change the carrier mobilities, we would also inevitably change a few other device parameters (e.g. the light absorption properties, and thus the value of $G_{C T, \text { area }}$ ). Therefore, the inclusion of experimental data into our analysis would complicate our explanation and understanding on this matter.

\subsection{Effect on Short-Circuit Current Density}

Figure 3 shows the magnitude of the short-circuit current density $\left(\left|J_{s c}\right|\right)$ as a function of $C$ for each of the studied $\mu_{n} / \mu_{p}$.
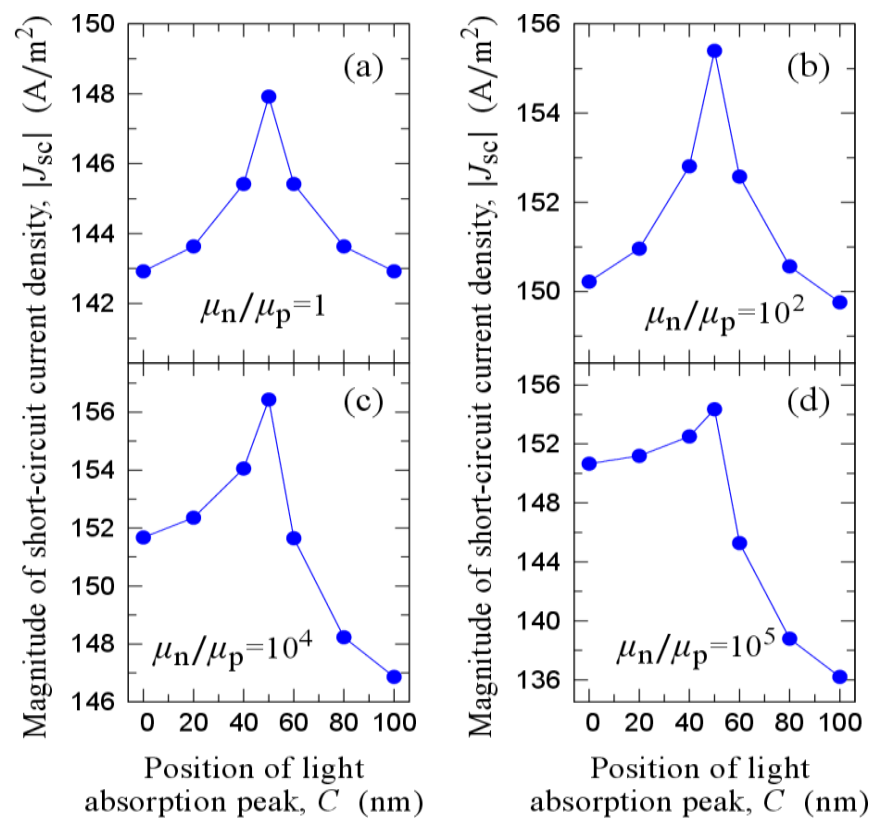

Fig. 3: Magnitude of the short-circuit current density $\left|J_{s c}\right|$ as a function of the position of the light absorption peak $C$ when (a) $\mu_{n} / \mu_{p}=1$, (b) $\mu_{n} / \mu_{p}=10^{2}$,

(c) $\mu_{n} / \mu_{p}=10^{4}$, and (d) $\mu_{n} / \mu_{p}=10^{5}$. If $\mu_{n} / \mu_{p}$ is increased to a value significantly above $10^{5},\left|J_{s c}\right|$ produced by the light absorption profile with $C<L / 2$ (e.g. $C=20 \mathrm{~nm}$ ) would even surpass $\left|J_{s c}\right|$ produced by the light absorption profile with $C=L / 2$.

To explain the trend shown in Fig. 3, let us explore the role of the drift and the diffusion currents. We define the average electron drift current density $\left\langle_{n, d r}\right\rangle$ and the average electron diffusion current density $\left\langle J_{n, \text { diff }}\right\rangle$ as

$$
\begin{aligned}
& \left\langle U_{n, d r}\right\rangle=q \mu_{n} F \int_{0}^{L} \frac{n_{n e t}}{L} d x=q \mu_{n} F\left\langle n_{n e t}\right\rangle \\
& \left\langle J_{n, \text { diff }}\right\rangle=q D_{n} \int_{0}^{L}\left(\frac{\partial n_{n e t}}{\partial x}\right) d x / L=q D_{n}\left\langle\frac{\partial n_{n e t}}{\partial x}\right\rangle
\end{aligned}
$$

where $\left\langle n_{n e t}\right\rangle$ is the average $n_{n e t}$ and $\left\langle\partial n_{n e t} / \partial x\right\rangle$ is the average $\partial n_{n e t} / \partial x$.

Table 3 shows $\left\langle J_{n, d r}\right\rangle$ 's and $\left\langle J_{n, d i f f}\right\rangle$ 's at short-circuit for the balanced mobility case $\left(\mu_{n} / \mu_{p}=1\right)$. As seen in Table 3 , as the light absorption is concentrated farther from the cathode (i.e. as $C$ is lowered), $\left\langle U_{n \text {,diff }}\right\rangle$ remains unchanged because $\left\langle\partial n_{n e t} / \partial x\right\rangle$ is 
unchanged, but the magnitude of $\left\langle_{n, d r}\right\rangle$ increases because $\left\langle n_{n e t}\right\rangle$ increases. Even when we assume there is no non-geminate recombination in our calculations (by using $\gamma=0$ and $k_{m n}=0 \mathrm{~s}^{-1}$ ), we find that $\left\langle n_{n e t}\right\rangle$ still increases if the light absorption is concentrated farther from the cathode. Therefore, the non-geminate recombination is not the deciding factor why $\left\langle n_{\text {net }}\right\rangle$ increases as $C$ is lowered.

Table 3: The average electron drift current density $\left\langle J_{n, d r}\right\rangle$ and the average electron diffusion current density $\left\langle\left\langle_{n, \text { diff }}\right\rangle\right.$ at short-circuit for the balanced mobility case $\left(\mu_{n} / \mu_{p}=1\right)$ calculated using $G_{C T}$ with different light absorption peak positions $C$ 's.

\begin{tabular}{ccc}
\hline $\boldsymbol{C}(\mathbf{n m})$ & $\left\langle_{\boldsymbol{n}, \boldsymbol{d r}}\right\rangle\left(\mathbf{A} \cdot \mathbf{m}^{-\mathbf{2}}\right)$ & $\left\langle\boldsymbol{J}_{\boldsymbol{n}, \text { diff }}\right\rangle\left(\mathbf{A} \cdot \mathbf{m}^{-\mathbf{2}}\right)$ \\
\hline 20 & $-1.19848 \times 10^{5}$ & $1.19762 \times 10^{5}$ \\
50 & $-1.19836 \times 10^{5}$ & $1.19762 \times 10^{5}$ \\
80 & $-1.19821 \times 10^{5}$ & $1.19762 \times 10^{5}$ \\
\hline
\end{tabular}

To rationalize why $\left\langle n_{n e t}\right\rangle$ increases as the light absorption is concentrated farther from the cathode (the electrode collecting free electrons), we consider the following two basic facts. First, the profile of the free electrons per unit volume at steady state (which is $n_{\text {net }}$ profile) is attained after some of the generated electrons are redistributed within the active layer (where some electrons may be (accidentally) extracted from the active layer during the redistribution process) and some of the electrons are involved in the nongeminate recombination. However, we can ignore the effect of recombination since we have shown that it is not the deciding factor. Second, the cathode has a higher Fermi level than the anode, and thus the resulting boundary conditions [18] mean that the free electrons (holes) must have a significantly higher concentration near the cathode (anode) than near the anode (cathode).

Now consider the $C=20 \mathrm{~nm}$ and $C=80 \mathrm{~nm}$ cases as shown in Table 3 . In both cases, the electric field magnitudes are the same since both cases are at the same applied voltage $V_{a}$ (i.e. at short-circuit). For the $C=20 \mathrm{~nm}$ case, there should be less free electrons extracted from the active layer in attaining $n_{\text {net }}$ than for the $C=80 \mathrm{~nm}$ case since majority of the electrons are generated farther from the cathode, and thus are less likely to be extracted during the redistribution process. This means more of the generated electrons are retained inside the active layer, thus causing a higher $n_{\text {net }}$ for the $C=20 \mathrm{~nm}$ case than for the $C=80 \mathrm{~nm}$ case. Therefore, the $C=20 \mathrm{~nm}$ case would give a higher magnitude of $\left\langle J_{n, d r}\right\rangle$ than the $C=80 \mathrm{~nm}$ case due to a higher magnitude of $n_{\text {net }}$ (see Eq. (17)).

From our analysis above, we can conclude that the farther the light absorption is concentrated from the cathode (anode), the more the free electrons (holes) are retained inside the active layer, and this gives a higher $\left|J_{n, d r}\right|\left(\left|J_{p, d r}\right|\right)$, but $\left|J_{n, \text { diff }}\right|\left(\left|J_{p, \text { diff }}\right|\right)$ is effectively unchanged because the gradient of $n_{\text {net }}\left(p_{\text {net }}\right)$ is effectively unchanged. Therefore, the farther the light absorption is concentrated from the cathode (anode), the higher the $\left|J_{n}\right|\left(\left|J_{p}\right|\right)$.

Based on the conclusion above, the results in Fig. 3(a) can be rationalized as follows. When $C=0 \mathrm{~nm}$ (i.e. when $C$ is the closest to the anode or the farthest from the cathode), $\left|J_{n}\right|$ is at its highest whereas $\left|J_{p}\right|$ is at its lowest. As we start increasing $C$ from $C=0 \mathrm{~nm}$, $\left|J_{p}\right|$ increases whereas $\left|J_{n}\right|$ decreases, where the increase in $\left|J_{p}\right|$ is stronger than the decrease in $\left|J_{n}\right|$, and hence $\left|J_{s c}\right|$ (i.e. $|J|$ at open-circuit) increases. Then, at one point, the 
decrease in $\left|J_{n}\right|$ equals to the increase in $\left|J_{p}\right|$, and at this optimum $C$, we have the peak $\left|J_{s c}\right|$. Then, as we further increase $C$ beyond the optimum $C,\left|J_{s c}\right|$ decreases since the decrease in $\left|J_{n}\right|$ is stronger than the increase in $\left|J_{p}\right|$. For $\mu_{n} / \mu_{p}=1$ case, the contribution from electrons (therefore $\left|J_{n}\right|$ ) and holes (therefore $\left|J_{p}\right|$ ) towards $\left|J_{s c}\right|$ are equal (since electrons and holes have the same mobilities), and therefore $\left|J_{s c}\right|$ as a function of $C$ is symmetric about $C=L / 2$ (i.e. the optimum $C$ ).

When $\mu_{n} / \mu_{p}=10^{2}$, the contribution of $\left|J_{n}\right|$ on $\left|J_{s c}\right|$ is stronger than the contribution of $\left|J_{p}\right|$ on $\left|J_{s c}\right|$ due to the fact that the electron mobility is higher now, and since $\left|J_{n}\right|$ is higher if $C$ is closer to the anode, therefore $\left|J_{s c}\right|$ produced by the profile with $C<L / 2$ (i.e. $C$ closer to the anode) is higher than $\left|J_{s c}\right|$ produced by the profile with $C>L / 2$. This explains the results shown in Fig. 3(b).

As $\mu_{n} / \mu_{p}$ is increased and becomes more imbalanced, the contribution of $\left|J_{n}\right|$ on $\left|J_{s c}\right|$ becomes even more significant, and this widens the difference between $\left|J_{s c}\right|$ produced by the profile with $C<L / 2$ and $\left|J_{s c}\right|$ produced by the profile with $C>L / 2$. This explains the trends as we increase $\mu_{n} / \mu_{p}$ from 1 to $10^{5}$ as shown in Fig. 3. Due to these trends, we can expect that when $\mu_{n} / \mu_{p}$ reaches a threshold value (when $\left.\mu_{n} / \mu_{p} \gg 10^{5}\right),\left|J_{s c}\right|$ produced by the profile with $C<L / 2$ would even surpass $\left|J_{s c}\right|$ produced by the profile with $C=L / 2$. It is worth noting that the explanation presented in section 3.1 is applicable at any given applied voltage $V_{a}$ in general, and not just at the short-circuit.

\subsection{Effect on Open-Circuit Voltage}

Figure 4 shows the open-circuit voltage $V_{o c}$ as a function of $C$ for each of the studied $\mu_{n} / \mu_{p}$. Note that at any given $\mu_{n} / \mu_{p}$, the trend of $V_{o c}$ as a function of $C$ is determined by the trend of $|J|$ (the magnitude of the total current density) as a function of $C$ at applied voltage $V_{a}$ near but lower than $V_{o c}$. This is because, at a given $V_{a}$ that is near but lower than $V_{o c}$, a higher $|J|$ means a higher $V_{o c}$ is expected since a higher extra $V_{a}$ is required in order to push and make $|J|=0$. For example, for the $\mu_{n} / \mu_{p}=1$ case at $V_{a}=0.7 \mathrm{~V}$ as shown in Fig. 5(a), the profile with $C=50 \mathrm{~nm}$ has a higher $|J|$ than the $|J|$ for the profile with $C=$ $20 \mathrm{~nm}$, and hence the profile with $C=50 \mathrm{~nm}$ has a higher $V_{o c}$ than the $V_{o c}$ for the profile with $C=20 \mathrm{~nm}$. Therefore, the trend of $V_{o c}$ shown in Fig. 4(a) can be explained by the trend of $|J|$ shown in Fig. 5(a), where the results shown in Fig. 5(a) can be rationalized in the same way as we rationalize the results shown in Fig. 3(a).

At high $V_{a}$ (near but below $V_{o c}$ ), the electric field magnitude is significantly lower and has significantly less influence in transporting and extracting the carriers than at shortcircuit. Hence, at high $V_{a}$, the light absorption profile (and thus $C$ ) becomes significantly more important in determining $n_{n e t}$ and $p_{\text {net }}$, and thus in determining $\left|J_{n}\right|,\left|J_{p}\right|$ and $|J|$, than at short-circuit. Consequently, $|J|$ at high $V_{a}$ is more sensitive to $C$ compared with $|J|$ at short-circuit (i.e. $\left|J_{s c}\right|$ ), and therefore the trend of $|J|$ at high $V_{a}$ as a function of $C$ for a given $\mu_{n} / \mu_{p}$ (where $\mu_{n} / \mu_{p}>1$ ) is equivalent to the trend of $\left|J_{s c}\right|$ as a function of $C$ but at a significantly higher $\mu_{n} / \mu_{p}$. That is why at a high $V_{a}$, the $|J|$ produced by the profile with $C<L / 2$ already surpasses the $|J|$ produced by the profile with $C=L / 2$ when $\mu_{n} / \mu_{p}=$ $10^{4}$ (see Fig. 5(c)) whereas at $V_{a}=0 \mathrm{~V}$ (i.e. short-circuit), $\left|J_{s c}\right|$ produced by the profile with $C<L / 2$ still does not surpass $\left|J_{s c}\right|$ produced by the profile with $C=L / 2$ when $\mu_{n} / \mu_{p}=10^{4}$ (see Fig. 3(c)). Figure 5 shows the trends of $|J|$ at high $V_{a}$ as a function of $C$ for each of the studied $\mu_{n} / \mu_{p}$, and the results shown in Fig. 5 give rise to the trends of $V_{o c}$ as a function of $C$ for each of the studied $\mu_{n} / \mu_{p}$ which is shown in Fig. 4. As mentioned at 
the end of section 3.1, the argument that we use to rationalize the results shown in Fig. 3 is applicable at any $V_{a}$, and therefore, the same argument can be used to rationalize the results shown in Fig. 5.
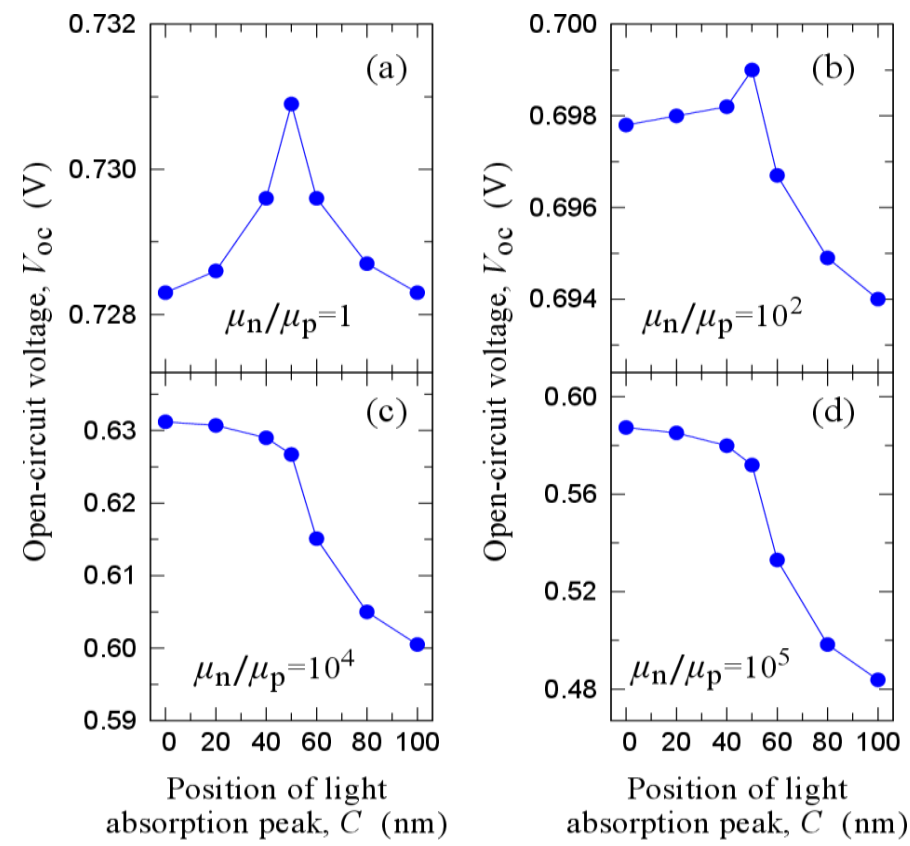

Fig. 4: Open-circuit voltage $V_{o c}$ as a function of the position of the light absorption peak $C$ when (a) $\mu_{n} / \mu_{p}=1$, (b) $\mu_{n} / \mu_{p}=10^{2}$, (c) $\mu_{n} / \mu_{p}=10^{4}$, and (d) $\mu_{n} / \mu_{p}=10^{5}$.
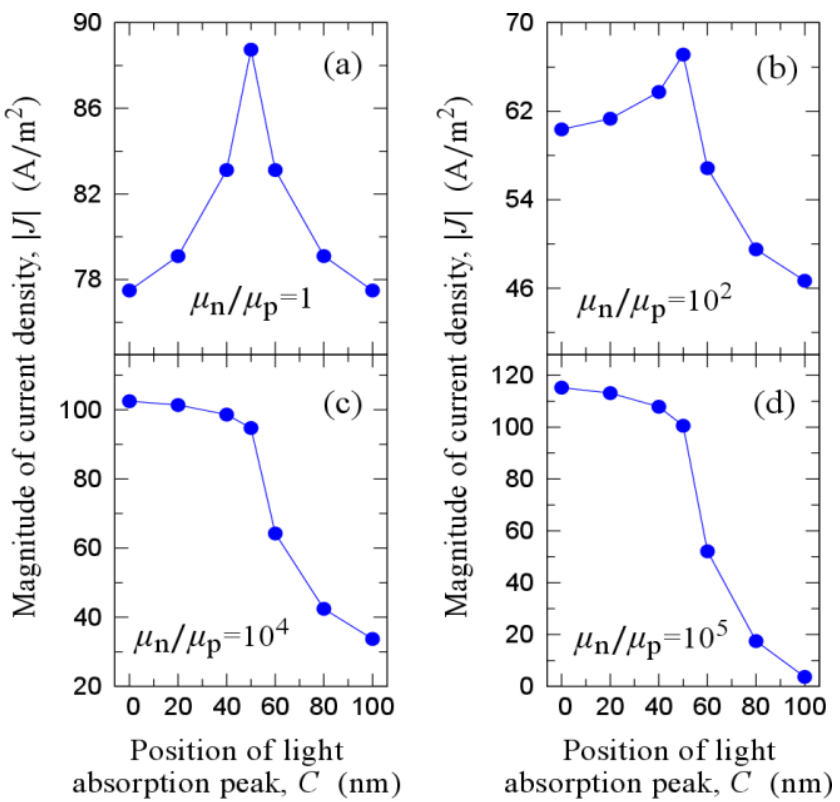

Fig. 5: Magnitude of the current density $|J|$ as a function of the position of the light absorption peak $C$ for (a) $\mu_{n} / \mu_{p}=1$ at $V_{a}=0.7 \mathrm{~V}$, (b) $\mu_{n} / \mu_{p}=10^{2}$ at $V_{a}=0.68$ $\mathrm{V}$, (c) $\mu_{n} / \mu_{p}=10^{4}$ at $V_{a}=0.58 \mathrm{~V}$, and (d) $\mu_{n} / \mu_{p}=10^{5}$ at $V_{a}=0.48 \mathrm{~V}$. The applied voltage $V_{a}$ used for each $\mu_{n} / \mu_{p}$ are chosen randomly but is close to the corresponding $V_{o c}$ (e.g. for $\mu_{n} / \mu_{p}=1$ case, $V_{o c}$ is around $0.73 \mathrm{~V}$ as shown in Fig. 4(a), so we consider $V_{a}=0.7 \mathrm{~V}$ here) 


\subsection{Effect on Fill Factor}

Figure 6 shows the fill factor (FF) as a function of $C$ for each of the studied $\mu_{n} / \mu_{p}$. To rationalize the trend of the FF as a function of $C$, it is important to note that the FF occurs somewhere between the short-circuit and the open-circuit. Hence, the trend of the FF as a function of $C$ at a given $\mu_{n} / \mu_{p}$ is simply somewhere between the trend of $\left|J_{s c}\right|$ and the trend of $V_{o c}$ as functions of $C$ for the same $\mu_{n} / \mu_{p}$. For the device considered in this study, the FF occurs at $V_{a}$ that is significantly closer to $V_{o c}$ than to the short-circuit, and hence the trends of the FF as a function of $C$ as shown in Fig. 6 is very similar to the trends of $V_{O C}$ as a function of $C$ as shown in Fig. 4.
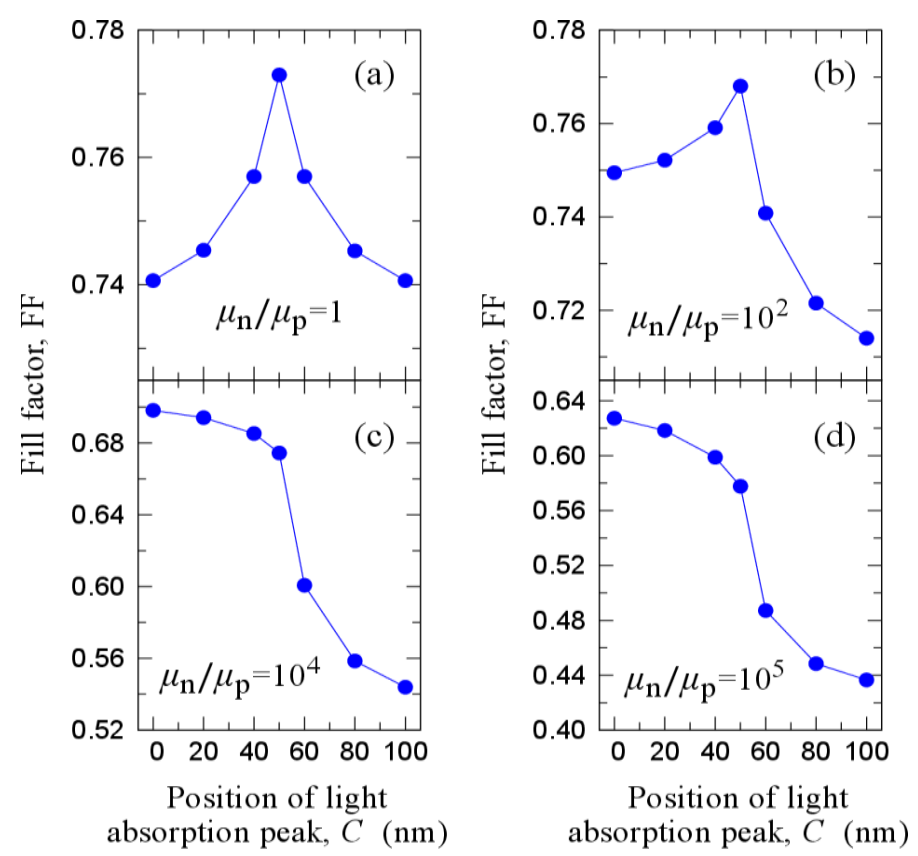

Fig. 6: Fill factor (FF) as a function of the position of the light absorption peak $C$ when (a) $\mu_{n} / \mu_{p}=1$, (b) $\mu_{n} / \mu_{p}=10^{2}$, (c) $\mu_{n} / \mu_{p}=10^{4}$, and (d) $\mu_{n} / \mu_{p}=10^{5}$.

Mescher et al. [14] concluded that enhanced light absorption at the two edges of the active layer (i.e. near the anode and the cathode) lead to a high unfavorable diffusion current which reduces the FF, whereas an enhanced absorption at the center of the active layer leads to a high FF. These conclusions partially agree with our results here. First, we find the drift current is the one that affects the dependence of $|J|$, and thus the dependences of $\left|J_{s c}\right|, V_{o c}$ and FF on the light absorption profile, whereas the diffusion current basically has no effect (see section 3.1). Second, we find that an enhanced light absorption at the center of the active layer leads to the best FF only if the mobility imbalance (i.e. $\mu_{n} / \mu_{p}$ ) is not very high (see Fig. 6).

Tress et al. [15] concluded that an enhanced absorption near the electrode collecting the slower carrier type would give a higher FF even when the mobility imbalance is very low, whereas Islam et al. [16] concluded that when the mobility imbalance is low, an enhanced absorption at the center of the active layer gives the best FF. We find that an enhanced absorption near the electrode collecting the slower carrier type (hole is the slower carrier type in our study here) would give the best FF only when the mobility imbalance is very high (see Fig. 6). When the mobility imbalance is not very high, the best FF is produced when the light absorption is concentrated at the center of the active layer. Therefore, our results here agree with the results from Islam et al. [16], but it is worth 
noting that they did not investigate the role of mobility imbalance on the optimum light absorption profile.

\subsection{Effect on Power Conversion Efficiency}

Figure 7 shows the power conversion efficiency (PCE) as a function of $C$ for each of the studied $\mu_{n} / \mu_{p}$. The PCE is given by

$$
P C E=F F \times\left|J_{s c}\right| \times V_{o c} / P_{i n}
$$

where $P_{\text {in }}$ is the input power per unit area of the incident light (taken to be under the 1 sun condition which is $1000 \mathrm{~W} / \mathrm{m}^{2}$ ). Hence, the trend of the PCE as a function of $C$ at a given $\mu_{n} / \mu_{p}$ is simply the combination of the trends of $\left|J_{s c}\right|, V_{o c}$ and FF as functions of $C$ for the same $\mu_{n} / \mu_{p}$. Therefore, the trends of the PCE shown in Fig. 7 can be understood by combining the trends shown in Fig. 3, Fig. 4, and Fig. 6.
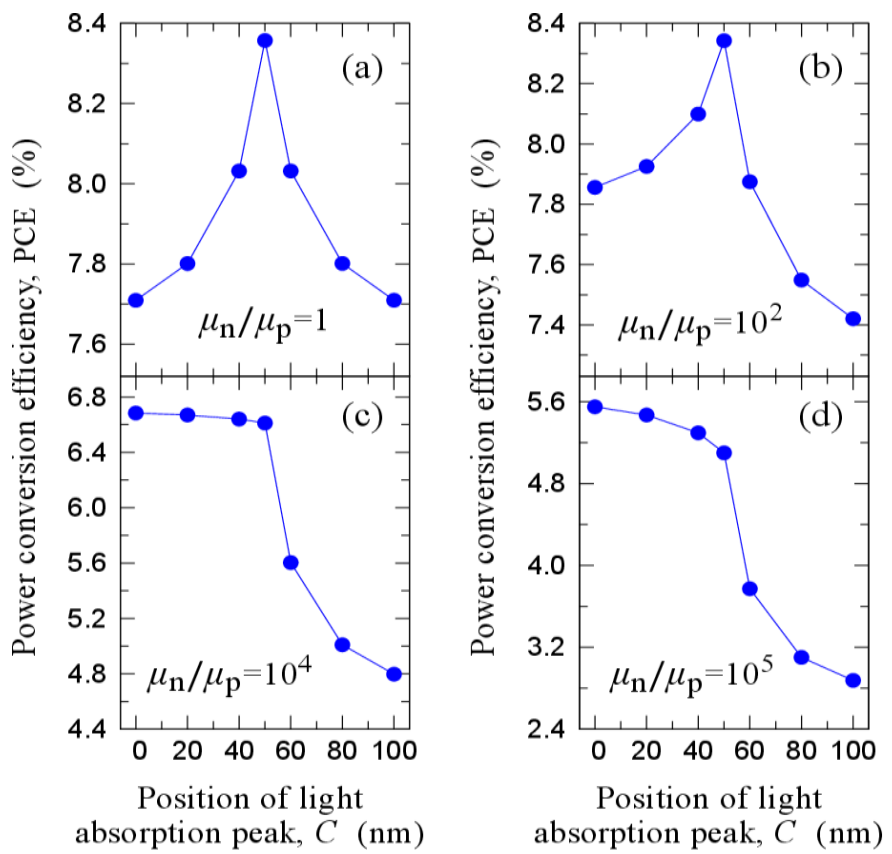

Fig. 7: Power conversion efficiency (PCE) as a function of the position of the light absorption peak $C$ when (a) $\mu_{n} / \mu_{p}=1$, (b) $\mu_{n} / \mu_{p}=10^{2}$, (c) $\mu_{n} / \mu_{p}=10^{4}$, and (d)

$$
\mu_{n} / \mu_{p}=10^{5} \text {. }
$$

According to Mescher et al. [14] and Islam et al. [16], the highest PCE is produced when the light absorption is concentrated at the center of the active layer. However, the conclusion is incomplete according to our results. We find that the highest PCE is produced by the light absorption that concentrates at the center of the active layer only when the mobility imbalance is not very high (see Fig. 7). However, when the mobility imbalance is very high (see Fig. 7), the best PCE is produced when the light absorption is concentrated near the electrode collecting the slower carrier type.

\section{CONCLUSION}

By using our updated current-voltage model for OPVs, we have investigated how the light absorption profile with an enhanced absorption at a certain position inside the active layer affects the performance of OPVs. It is found that the light absorption profile affects the OPV performance through the drift current. The further the light absorption is 
concentrated from the electrode collecting a given charge carrier type, the higher the drift current and the total current for that carrier type, whereas the diffusion current for that carrier type is unaffected. When the carrier mobilities are balanced, the best $\left|J_{s c}\right|, V_{o c}$, FF and PCE are produced by the light absorption that concentrates at the center of the active layer. When the mobilities become imbalanced, the $\left|J_{s c}\right|, V_{o c}$, FF and PCE produced by the light absorption that concentrates nearer to the electrode collecting the slower carrier type improve relative to the ones produced by the light absorption that concentrates at other positions inside the active layer. When the mobility imbalance is high enough (i.e. reach a threshold value), the best $\left|J_{s c}\right|, V_{o c}, \mathrm{FF}$ and PCE are produced by the light absorption that concentrates near the electrode collecting the slower carrier type. The mobility imbalance threshold values for $\left|J_{s c}\right|, V_{o c}, \mathrm{FF}$, and PCE are different, where the threshold value for $V_{o c}$ is the lowest, whereas the threshold value for $\left|J_{s c}\right|$ is the highest. Therefore, if the mobility imbalance is not very high (when the ratio of the mobility of the faster carrier to the mobility of the slower carrier is less than about $10^{3}$ ), it is important to ensure that the light absorption is concentrated at the center of the active layer in order to maximize the PCE. However, if the mobility imbalance is very high (when the ratio of the mobility of the faster carrier to the mobility of the slower carrier is about $10^{4}$ or more), the light absorption should be concentrated near the electrode collecting the slower carrier type in order to maximize the PCE.

\section{ACKNOWLEDGEMENT}

This work was supported by the Ministry of Higher Education Malaysia under the Fundamental Research Grant Scheme (grant no. FRGS/1/2017/STG02/UIAM/03/2).

\section{REFERENCES}

[1] Scharber MC, Sariciftci NS. (2013) Efficiency of bulk-heterojunction organic solar cells. Progress in Polymer Science, 38(12): 1929-1940. doi: 10.1016/j/progpolymsci.2013.05.001.

[2] Park Sungjun, Heo SW, Lee W, Inoue D, Jiang Z, Yu K, Jinno H, Hashizume D, Sekino M, Yokota T, Fukuda K, Tajima K, Someya T. (2018) Self-powered ultraflexible electronics via nano-grating-patterned organic photovoltaics. Nature, 561(7724): 516-521. doi: 10.1038/s41586-018-0536-x.

[3] Teng N, Yang S, Chen F. (2018) Plasmonic - Enhanced organic photovoltaic devices for low-power light applications. IEEE Journal of Photovoltaic, 8(3): 752-756. doi: 10.1109/JPHOTOV.2018.2797975.

[4] Green MA, Emery K, Hishikawa Y, Warta W, Dunlop ED. (2016) Solar cell efficiency tables. Progress in Photovoltaics, 24(7): 905-913. doi: 10.1002/pip.2788.

[5] Meng L, Zhang Y, Wan X, Li C, Zhang X, Wang Y, Ke X, Xiao Z, Ding L, Xia R, Yip H, Cao Y, Chen Y. (2018) Organic and solution-processed tandem solar cells with $17.3 \%$ efficiency. Science, 361(6407): 1094-1098. doi: 10.1126/science.aat2612.

[6] Mandoc MM, Koster LJA, Blom PWM. (2007) Optimum charge carrier mobility in organic solar cells. Applied Physics Letter, 90(13): 133504. doi: 10.1063/1.2711534.

[7] Inche Ibrahim ML, Ahmad Z, Sulaiman K, Muniandy SV. (2014) Combined influence of carrier mobility and dielectric constant on the performance of organic bulk heterojunction solar cells. AIP Advance, 4(5): 057133. doi: 10.1063/1.4881080.

[8] Lee JJ, Lee SH, Kim FS, Choi HH, Kim JH. (2015) Simultaneous enhancement of the efficiency and stability of organic solar cells using PEDOT:PSS grafted with a PEGME buffer layer. Organic Electronics, 26: 191-199. doi: 10.1016/j.orgel.2015.07.022.

[9] Chen A, Zhu K, Shao Q, Ji Z. (2016) Understanding the effects of TCO work function on the performance of organic solar cells by numerical simulation. Semiconductor Science and Technology, 31(6): 065025. doi: 10.1088/0268-1242/31/6/065025. 
[10] Koster LJA, Shaheen SE, Hummelen JC. (2012) Pathways to a new efficiency regime for organic solar cells. Advanced Energy Materials, 2(10): 1246-1253. doi: 10.1002/aen.201200103.

[11] Inche Ibrahim ML, Hassan HA. (2019) Influence of active layer thickness on the performance of organic photovoltaics with light trapping. IEEE Transaction Electron Devices, 66(7): 3124-3128. doi: 10.1109/TED.2019.2917594.

[12] Lenes M, Koster LJA., Mihailetchi VD, Blom PWM. (2006) Thickness dependence of the efficiency of polymer:fullerene bulk heterojunction solar cells. Applied Physics Letter, 88(24): 243502. doi: 10.1063/1.2211189.

[13] Fallahpour AH, Gagliardi A, Gentilini D, Zampetti A, Santoni F, Auf Der Maur M, Carlo AD. (2014) Optoelectronic simulation and thickness optimization of energetically disordered organic solar cells. Journal Computational Electronics, 13(4): 933-942. doi: 10.1007/s10825-014-0611-y.

[14] Mescher J, Christ N, Kettlitz S, Colsmann A, Lemmer U. (2012) Influence of the spatial photocarrier generation profile on the performance of organic solar cells. Applied Physics Letters, 101(7): 073301. doi: 10.1063/1.4745510.

[15] Tress W, Merten A, Furno M, Hein M, Leo K, Riede M. (2013) Correlation of absorption profile and fill factor in organic solar cells: The role of mobility imbalance. Advanced Energy Materials, 3(5): 631-638. doi: 10.1002/aenm.201200835.

[16] Islam M, Wahid S, Chowdhury M, Hakim F, Alam M. (2017) Effect of spatial distribution of generation rate on bulk heterojunction organic solar cell performance: A novel semianalytical approach. Organic Electronics, 46(7): 226-241. doi: 10.1016/j.orgel.2017.04.021.

[17] Gan Q, Bartoli FJ, Kafafi ZH. (2013) Plasmonic-enhanced organic photovoltaics: breaking the $10 \%$ efficiency barrier. Advanced Materials, 25(17): 2385-2396. doi: 10.1002/adma.201203323.

[18] Inche Ibrahim ML. (2018) An analytical model for organic solar cells incorporating nongeminate monomolecular and bimolecular recombinations. Semiconductor Science and Technology, 33(12): 125005. doi: 10.1088/1361-6641/aadf72.

[19] Inche Ibrahim ML. (2017) Dissociation of charge-transfer states at donor-acceptor interfaces of organic heterojunctions. Journal of Physics D: Applied Physics, 50(6): 065103. doi: 10.1088/1361-6463/50/6/065103.

[20] Braun CL. (1984) Electric field assisted dissociation of charge transfer states as a mechanism of photocarrier production. The Journal Chemical Physics, 80(9): 4157-4161. doi: $10.1063 / 1.447243$.

[21] Kniepert J, Lange I, van der Kaap NJ, Koster LJA, Neher D. (2014) A conclusive view on charge generation, recombination, and extraction in as-prepared and annealed P3HT:PCBM blends: Combined experimental and simulation work. Advanced Energy Materials, 4(7): 1301401. doi: 10.1002/aenm.201301401. 